\title{
Comportamento da precipitação pluvial no município de Cáceres Pantanal Mato-Grossense no período de 1971 a 2011
}

\author{
Rainfall behavior in the municipality of Cáceres Pantanal of Mato Grosso in the \\ period 1971 to 2011
}

\section{Maria Cândida Moitinho NUNES'; Sandra Mara Alves da Silva NEVES²; Ronaldo José NEVES²; Jonas Teixeira NERY3}

\begin{abstract}
${ }^{1}$ Autora para correspondência. Doutora e Professora Adjunta. Universidade Federal de Pelotas, Faculdade de Agronomia Eliseu Maciel (FAEM/UFPEL), Departamento de Solos. Campus Universitário $s / n$. Capão do Leão-RS, Brasil - 96010-610. nunes.candida@gmail.com

${ }^{2}$ Doutor e Professor Adjunto. Universidade do Estado de Mato Grosso.ssneves@unemat.br; rjneves@terra.com.br

${ }^{3}$ Doutor e Professor Adjunto. Universidade Estadual Paulista. jonas@ourinhos.unesp.br
\end{abstract}

Recebido em: 11-09-2014; Aceito em: 21-04-2016

\begin{abstract}
Resumo
A precipitação pluvial (PP) tem função essencial na definição do clima e do potencial agrícola de uma região, e o conhecimento de seu comportamento ao longo do tempo é imprescindível para o monitoramento dos impactos causados pelo excesso ou pela falta prolongada de chuva. Foram utilizados dados mensais pluviométricos do Instituto Nacional de Meteorologia, referentes à estação de Cáceres-MT, no período de 1971 a 2011. Para análise da variabilidade da PP, utilizaram-se parâmetros estatísticos descritivos. A definição das estações seca e chuvosa foi realizada por meio de duas metodologias. Foi realizada também a avaliação da magnitude da seca no município. A PP anual de Cáceres é de $1.320,4 \mathrm{~mm}$, sendo que o mês com maior PP é janeiro $(251,9 \mathrm{~mm})$ e o de menor PP é agosto $(15,5 \mathrm{~mm})$. A PP apresentou tendência de redução ao longo da série. Cáceres apresentou duas estações bem definidas, com período chuvoso de novembro a março e período seco de abril a outubro. Na época de estiagem, a seca foi classificada como extrema $(I>-0,6)$ na maior parte do período de estudo.
\end{abstract}

Palavras-chave adicionais: agropecuária; clima; índice de seca; variabilidade temporal.

\begin{abstract}
Rainfall has key role in shaping the climate and the agricultural potential of the region and knowledge of the behavior of rainfall over time is essential for monitoring the impacts caused by excessive or prolonged lack thereof. We used monthly rainfall data from the National Institute of Meteorology (INMET), referring to the station Caceres-MT in the period from 1971 to 2011. For analysis of rainfall variability we used descriptive statistical parameters. The definition of wet and dry seasons was performed by two methods. It was also performed to evaluate the extent of drought in the county. The average annual rainfall of $1320.4 \mathrm{~mm}$ Caceres is, being the month with the highest average rainfall is January $(251.9 \mathrm{~mm})$ and the month with the lowest average precipitation is August $(15.5 \mathrm{~mm})$. The precipitation tended to decrease throughout the series. Caceres has two distinct seasons, with the rainy season from November to March and the dry season from April to October. In the dry season, drought was classified as extreme $(I>-0.6)$ in most of the study period.
\end{abstract}

Additional keywords: agricultural; climate; drought index; temporal variability.

\section{Introdução}

A precipitação pluvial (PP) tem grande importância na caracterização do clima de uma região, interferindo nas alternâncias de produtividade das culturas (Silva et al., 2003), e está diretamente relacionada a diversos setores, pois o regime pluviométrico afeta a economia, o meio ambiente e a sociedade, como um todo (Silva et al., 2007), o que evidencia a importância da PP na expressão do clima e do potencial agrícola de uma região (Sousa \& Nery, 2002). A PP é um dos elementos climáticos mais diretamente relacionados à produção agrícola, e seu caráter aleatório aumenta os riscos na programação das atividades desse setor (Melo Junior et al., 2006).

O conhecimento do comportamento da PP ao longo do tempo é imprescindível para o monitoramento dos impactos causados pelo excesso ou pela falta prolongada de chuva. Do ponto de vista agrícola, as principais questões sobre estação chuvosa são relativas ao mês de início e fim, precipitação total no período e sua intensidade (Sansigolo, 1996). O conhecimento dos totais de chuva constitui elemento importante na determinação das vazões superficiais e, consequentemente, de suas disponi- 
bilidades para um perfeito gerenciamento do recurso hídrico (Salgueiro, 2005).

No Pantanal mato-grossense, considerado como a maior planície inundada da América do Sul, a irregularidade da PP pode influenciar nas atividades agropecuárias. A posição geográfica do Pantanal mato-grossense é peculiar, constituindo o elo entre a Amazônia, o Cerrado e os Chacos Boliviano e Paraguaio, sendo considerado como um conjunto de vários ecossistemas provenientes dos rios da Bacia do Alto Paraguai - BAP (Cunha \& Junk, 2004). Essa bacia possui grandes áreas de exploração agrícola e pecuária, entre as quais podem ser destacadas culturas como soja, milho, cana-de-açúcar e criação animal, principalmente a produção de gado de corte (Collischonn et al., 2003). Segundo Buriol et al. (2007), a quantidade e a distribuição de chuvas que ocorrem anualmente em uma região determinam o tipo de vegetação natural e também o modo de exploração agrícola predominante.

$O$ conhecimento da PP pode influenciar também nas previsões de alagamentos, cuja ocorrência na Bacia do Alto Paraguai comprometeria diversas cidades e fazendas situadas na planície pantaneira. O regime pluviométrico no Pantanal influencia os regimes de cheia e de seca, os quais condicionam a disponibilidade de pastagens para o gado. Em anos de cheia, as áreas mais baixas, que possuem pastagens de melhor qualidade, ficam cobertas por água, durante períodos que dependem da intensidade e de duração da precipitação, prejudicando a pecuária (Soriano \& Galdino, 2005). Não obstante, todos os anos ocorrem incêndios nas subregiões pantaneiras de Mato Grosso. Segundo Batista (2000), isto se deve à distribuição das chuvas; pois, se em determinado local esta ocorre de forma uniforme durante todo o ano, sem uma estação seca definida, o potencial de ocorrência e de propagação de incêndios é menor do que em local onde a estação chuvosa está concentrada em alguns meses, com longos períodos de estiagem.

Devido aos inúmeros benefícios que o Pantanal mato-grossense proporciona aos Estados de Mato Grosso e Mato Grosso do Sul, é evidente a preocupação com a vulnerabilidade hidrológica que afeta não somente a fauna e a flora, como também as mudanças climáticas, as quais podem alterar as vazões dos rios, bem como os elementos que dão sustentabilidade a este bioma, que exerce reflexo na sociedade e na economia das cidades que dele dependem (Diniz et al., 2008). Além disso, a região apresenta condições climáticas caracterizadas por PP e temperaturas elevadas, o que, geralmente, favorece ocorrências de endemias, a exemplo da relação positiva com a transmissão de dengue, cujo conhecimento desse processo poderá propiciar maior entendimento sobre a dinâmica de transmissão e consequentemente contribuir para o seu controle (Forattini, 2002).

No município de Cáceres, o período de maior concentração de PP (62,68\%) ocorre de dezembro a março, sendo que o mês de janeiro é o mais chuvoso. Nesta região, o período de maior estiagem ocorre de junho a agosto, com apenas $4,9 \%$ do total pluviométrico anual (Neves et al., 2011). Este comportamento evidencia a necessidade de identificar claramente o período de seca meteorológica, o qual pode afetar drasticamente uma região, além de provocar graves danos econômicos e sociais.

A análise das séries climáticas, visando a destacar possíveis periodicidades existentes, é fundamental para o planejamento de inúmeras atividades econômicas, sociais, entre outras (Silva et al., 2005). Em algumas situações, é importante caracterizar o regime pluviométrico de um determinado local e região através de coeficientes que representem de forma mais adequada o elemento em estudo, neste caso a precipitação.

Em virtude da função que a precipitação exerce na dinâmica ambiental e no desenvolvimento das atividades econômicas, objetivou-se investigar o comportamento da precipitação pluviométrica anual e mensal no município brasileiro de Cáceres/MT Pantanal Mato-Grossense, no período de 1979 a 2011.

\section{Material e métodos}

A fundação do município de Cáceres tem suas origens vinculadas ao século XVIII, mais precisamente no ano de 1772. Cáceres está localizada na região sudoeste mato-grossense,

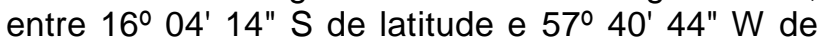
longitude, com uma população de 87.942, distribuída numa área de 24.351,44 km² (IBGE, 2014). O município integra a mesorregião CentroSul mato-grossense e a microrregião do Alto Pantanal, distando 215 km de Cuiabá-MT.

O clima do município de Cáceres, inserido nos biomas Pantanal, Amazônia e Cerrado, segundo a classificação de Köppen, é do tipo Tropical quente e úmido, com inverno seco $(A w)$. A temperatura máxima anual é de $32^{\circ} \mathrm{C}$, e a mínima, de $21^{\circ} \mathrm{C}$. No entanto, as máximas diárias na primavera podem ultrapassar $41^{\circ} \mathrm{C}$ (Neves et al., 2011).

Foram utilizados neste trabalho dados mensais pluviométricos da estação Cáceres (OMM 83405), relativos ao período de 1971 a 2011 (série de 41 anos de dados), disponibilizados pelo Instituto Nacional de Meteorologia (INMET), instalada no Instituto Federal de Educação, Ciência e Tecnologia de Mato Grosso (IFMT), com latitude de $16^{\circ} 03^{\prime} S$, longitude de $57^{\circ} 41^{\prime} \mathrm{W}$ e altitude de $118 \mathrm{~m}$. Os dados referem-se às precipitações pluviais mensais e anuais expressas em altura de lâmina d'água ( $\mathrm{mm})$.

Para a análise da variabilidade anual e mensal da precipitação pluvial durante o período, utilizaram-se os seguintes parâmetros estatísticos descritivos: 


$$
\begin{aligned}
& \bar{x}=\frac{\sum_{i=1}^{n} x_{i}}{n} \\
& S=\sqrt{\frac{\sum_{i=1}^{n}\left(x_{i}-\bar{x}\right)^{2}}{n-1}} \\
& C V=\frac{S}{\bar{x}} 100 \%
\end{aligned}
$$

Em que: $\bar{x}$ é a média anual ou mensal de precipitação pluvial no período $(\mathrm{mm})$; $x_{i}$ é o valor da precipitação pluvial no ano ou mês i $(\mathrm{mm})$; $n$ é o número de observações; S é o desvio-padrão $(\mathrm{mm})$; CV é o coeficiente de variação (\%).

Para a definição das estações seca e chuvosa, foi utilizado o método de Lima et al. (2008), o qual considera o valor médio mensal obtido da precipitação pluvial média anual, acumulada no período da série, que no caso de Cáceres é de $110 \mathrm{~mm}$. Considerando esse valor como limite entre as duas estações, fez-se a diferença do valor médio de cada mês por ele, identificando os valores negativos como meses de seca, e os positivos, como os chuvosos, servindo de balizamento para a interpretação da análise temporal da série.

Foi utilizado também o método descrito por Nery et al. (2002), o qual considera a percentagem da contribuição da média de cada mês em relação à precipitação média acumulada anual. Esses autores salientam que, se todos os meses do ano contribuíssem em relação ao total anual com a mesma precipitação, existiria a contribuição de $1 / 12$ do total anual $(8,3 \%)$, e que este valor pode ser adotado para a definição dos meses de seca.

$\mathrm{Na}$ avaliação da magnitude de seca em Cáceres, foram considerados os períodos de novembro de um dado ano a março do outro (chuvoso) e de abril a outubro do mesmo ano (seco), utilizando o índice proposto por Moreno (1994):

$\mathrm{I}=\left(\frac{\mathrm{p}-\mathrm{P}}{\mathrm{P}}\right)$

Em que: I é o índice de seca; $p$ a chuva total do período seco ou chuvoso $(\mathrm{mm})$ e $\mathrm{P}$ a chuva média no período - média climatológica $(\mathrm{mm})$. Os resultados obtidos da aplicação do índice de seca foram classificados em: $\mathrm{I} \geq-0,2=$ situação normal; $0,2>1 \geq-0,4=$ seca moderada; $-0,4>1 \geq-0,6=$ = seca intensa; $\mathrm{e} \mathrm{I}>-0,6=$ seca extrema.

Para a classificação da variabilidade dos atributos analisados, foram adotados os limites de coeficiente de variação $(\mathrm{CV})$, propostos por Warrick \& Nielsen (1980): CV < 12\%, $12 \%<$ CV < $60 \%$ e CV > $60 \%$, considerados de baixa, média e alta variabilidade, respectivamente.

\section{Resultados e discussão}

A precipitação pluvial (PP) total anual de Cáceres, no período de 1971 a 2011, foi de $1.320,4 \mathrm{~mm}$. O mês com maior PP foi janeiro (251,9 mm), que representa $19,1 \%$ da PP total anual. Por outro lado, o mês com menor PP foi agosto, com $15,5 \mathrm{~mm}$, o que corresponde a $1,3 \%$ da PP total média anual.

Tabela 1 - Estatística descritiva da precipitação pluvial anual e mensal no município de Cáceres- MT, no

\begin{tabular}{|c|c|c|c|c|c|}
\hline \multirow{2}{*}{ Meses } & $\bar{x}$ & Mínima & Máxima & \multirow[t]{2}{*}{$S$} & \multirow{2}{*}{$\begin{array}{l}\text { CV } \\
\text { (\%) }\end{array}$} \\
\hline & \multicolumn{3}{|c|}{-- } & & \\
\hline Jan. & 251,9 & 106,0 & 536,2 & 100,9 & 40,1 \\
\hline Fev. & 196,6 & 69,9 & 472,3 & 85,1 & 43,3 \\
\hline Mar. & 177,5 & 59,3 & 309,4 & 64,3 & 36,2 \\
\hline Abr. & 100,2 & 1,8 & 288,8 & 62,1 & 62,0 \\
\hline Maio & 41,8 & 0,4 & 141,7 & 36,1 & 86,3 \\
\hline Jun. & 20,4 & 0,0 & 92,6 & 23,0 & 112,6 \\
\hline Jul. & 18,1 & 0,0 & 142,9 & 29,4 & 162,9 \\
\hline Ago. & 17,5 & 0,0 & 93,2 & 22,6 & 129,6 \\
\hline Set. & 49,2 & 0,0 & 142,6 & 39,0 & 79,4 \\
\hline Out. & 86,8 & 25,4 & 215,0 & 44,5 & 51,3 \\
\hline Nov. & 145,5 & 27,8 & 355,0 & 73,8 & 50,8 \\
\hline Dez. & 215,0 & 99,0 & 412,5 & 74,9 & 34,8 \\
\hline Ano & 1320,4 & 944,3 & 1872,7 & 196,0 & 14,9 \\
\hline
\end{tabular}
período de 1971 a 2011. Descriptive statistics of annual and monthly rainfall in the municipality of Caceres (MT) in the period 1971-2011.

$\overline{\mathrm{X}}=$ média mensal; $\mathrm{S}=$ Desvio-Padrão; $\mathrm{CV}=$ coeficiente de variação. 
O mês de janeiro apresentou o maior valor máximo de PP da série de dados $(536,2 \mathrm{~mm})$, o qual ocorreu no ano de 1974. Neste mês, o menor valor de PP foi de 106,0 mm, no ano de 1993. No município de Cáceres, é comum não ocorrerem PPs nos meses de junho a setembro (Tabela 1). Resultados semelhantes foram obtidos por Silva et al. (2003), com dados registrados em 62 anos de precipitação em Uberaba (MG) e por Lima et al. (2008), com 63 anos de dados de Alegre (ES). Na série de 41 anos de dados em estudo, observou-se que $70,7 \%$ do período ocorreram, em um ou mais meses do ano, precipitações menores que $1,0 \mathrm{~mm}$.

O desvio-padrão para os dados de precipitação foi de 196,0 mm. Em estudo sobre o regime pluviométrico do arco das nascentes do Rio Paraguai, Martins et al. (2011) obtiveram desvio-padrão de $187,7 \mathrm{~mm}$, para o período de 1961 a 2008, em Cáceres, considerado pelos autores a menor variação interanual de PP da região.

Os resultados de coeficientes de variação (CV) da PP mensal (Tabela 1), segundo a classificação proposta por Warrick \& Nielsen (1980), apresentaram valores diferenciados conforme a época de ocorrência da PP. No período mais chuvoso, o mês de dezembro foi o que apresentou menor $\mathrm{CV}$, considerado como médio (34,8\%). Entretanto, no período de maior estiagem, o mês de julho foi o que apresentou maior CV $(162,9 \%)$, classificado como alto. Resultados semelhantes foram encontrados por Lima et al. (2008), no estudo da variabilidade temporal da PP mensal em Alegre (ES). Segundo Silva et al. (2003), que trabalharam com dados de Uberaba (MG), a ausência total de chuvas em alguns anos da série, nos meses de seca, pode ser a explicação dessa maior variabilidade, também encontrada pelos autores.

A PP anual apresentou um CV classificado como médio, de 14,9\% (Tabela 1). Lima et al. (2008) obtiveram resultados semelhantes. Segundo os autores, esse resultado ocorre porque é o somatório da PP anual, em que ocorre uma compensação dos meses de pouca chuva com os de maior intensidade, mantendo menor variabilidade entre a acumulada anual do que entre os meses, em diferentes anos.

De forma geral, nos primeiros 20 anos da série em estudo (1971 a 1990), a PP apresentou valores médios anuais acumulados $(1338,7 \mathrm{~mm}$ ) maiores do que os dos últimos 21 anos (1991 a 2011) da série de dados, em que a PP anual foi de $1.292,9 \mathrm{~mm}$, o que representou redução de $45,8 \mathrm{~mm}$ entre esses períodos (Figura 1).

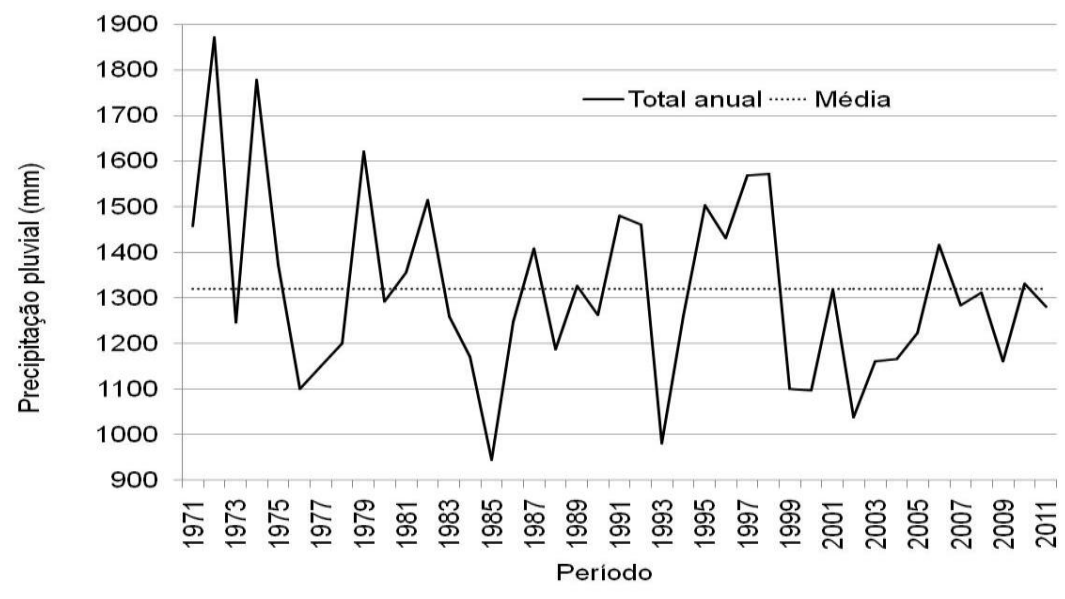

Figura 1 - Precipitação pluvial total anual no município de Cáceres- MT, no período de 1971 a 2011. Average total annual rainfall in the municipality of Caceres (MT) in the period 1971-2011.

Bieras \& Santos (2006) estudaram a precipitação pluviométrica de Bebedouro-SP, no período de 1983 a 2003, e observaram redução nos valores médios de PP na segunda metade da série de dados.

Verificou-se tendência de redução da PP total anual ao longo da série de dados em estudo. Ao se considerar os últimos 13 anos (a partir de 1999), a PP no município de Cáceres foi de $1.222,4 \mathrm{~mm}$, o que representou redução de $98,0 \mathrm{~mm}$ em relação à média de todo o período, que é de $1.320,4 \mathrm{~mm}$. Esse resultado pode comprometer ainda mais a disponibilidade de água para agropecuária na região, a qual apresenta déficit hídrico de 400,3 mm (Neves et al., 2011).
Semelhantemente aos resultados obtidos pela metodologia de Lima et al. (2008), para definir a estação seca e a chuvosa, o cálculo do percentual da PP mensal, conforme metodologia de Nery et al. (2002), indica que a estação seca correspondeu ao período de abril a outubro, e o período chuvoso, de novembro a março (Figura 3).

A PP mensal obtida foi de $110,0 \mathrm{~mm}$, considerando esse valor como limite entre as estações, conforme metodologia de Lima et al. (2008), e os meses de abril a outubro devem ser considerados como período de seca, enquanto de novembro a março, o período chuvoso (Figura 2). 


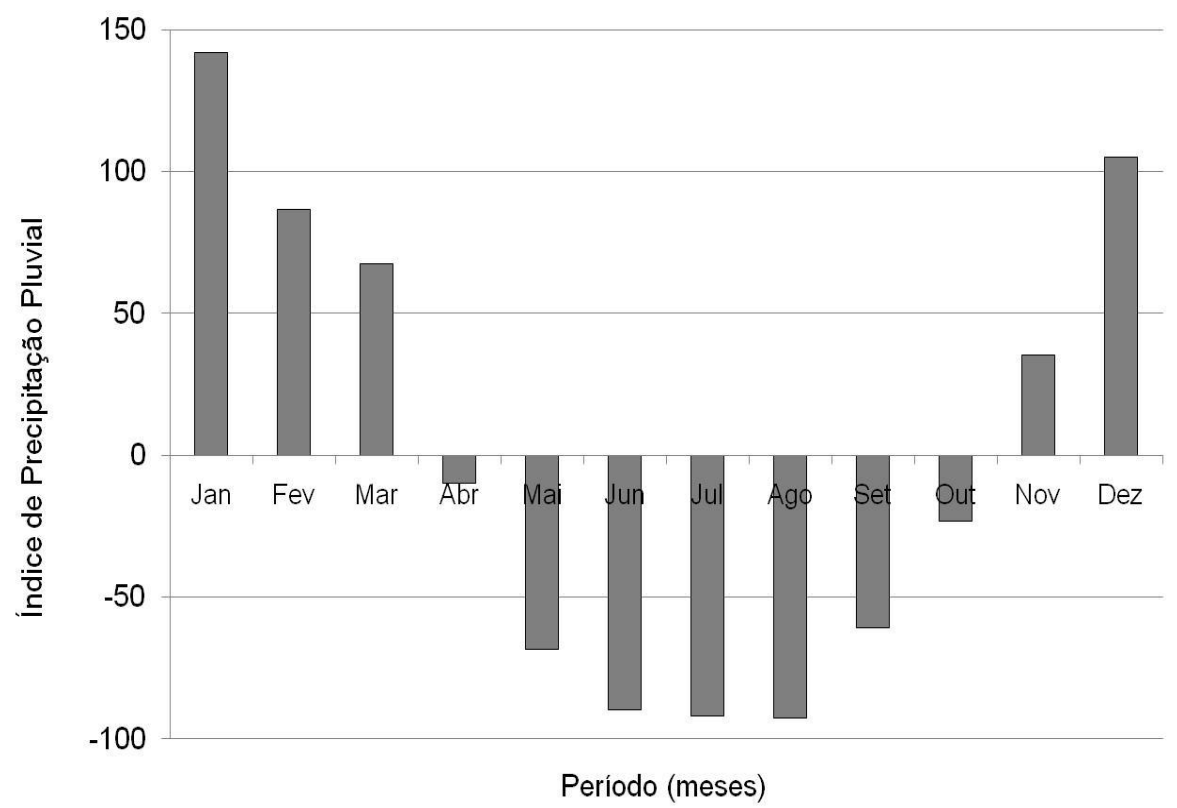

Figura 2 - Índice de precipitação pluvial para $110 \mathrm{~mm}$ de média mensal, para o município de Cáceres-MT, no período de 1971 a 2011 . Rainfall levels to $110 \mathrm{~mm}$ average monthly rainfall for the municipality of Caceres (MT) in the period 1971-2011.

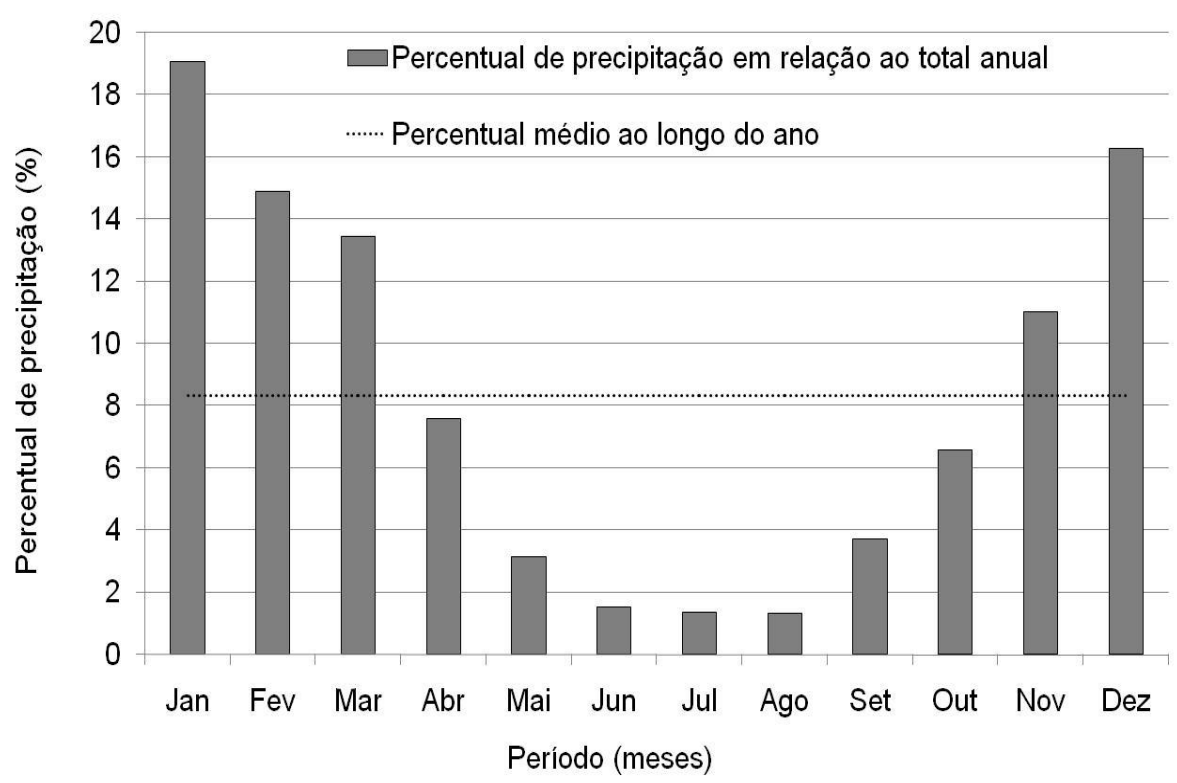

Figura 3 - Percentual da precipitação pluvial mensal, para o município de Cáceres-MT, no período de 1971 a 2011. Percentage of the average monthly rainfall for the municipality of Caceres (MT) in the period 1971-2011.

Na metodologia de Nery et al. (2002), o valor limite para a separação entre as estações seca e chuvosa é caracterizado por percentuais de precipitação menores que $8,3 \%$, valor este que corresponde a $1 / 12$ do total anual de precipitação. Pizzato et al. (2012), no estudo da distribuição e da probabilidade de ocorrência de precipitação em Cáceres-MT, considerando o período de 26 anos, obtiveram resultados diferentes. Segundo os autores, a estação seca corresponde ao período de maio a setembro, e a estação chuvosa, de outubro a abril.

No trabalho de Neves et al. (2011), considerando o balanço hídrico, o período de maior concentração pluvial no município de Cáceres ocorreu de dezembro a março. Esta consideração dos autores decorre do fato de que, neste período, considerando a capacidade de água disponível (CAD) de $100 \mathrm{~mm}$, o balanço hídrico climático no município não apresenta déficit hídrico. Entretanto, Cadavid García (1984), a partir da análise da PP de Cáceres, num período de 
10 anos (1971 a 1981), estimou que $82,4 \%$ da chuva anual de $1.262 \pm 46 \mathrm{~mm}$ (intervalo de confiança de $90,0 \%$ ) concentram-se no período de outubro a março.

Marcuzzo et al. (2011) estudaram a PP de 1977 a 2006 para Mato Grosso e verificaram que o período chuvoso no Estado compreende os meses de setembro a abril, e o período seco, de maio a agosto. No município de Alta Floresta, extremo norte de Mato
Grosso, Caioni et al. (2014) também verificaram a presença de duas estações bem definidas; entretanto, a estação seca ocorre de maio a setembro, e a chuvosa, de outubro a abril.

De acordo com os valores da PP mensal de Cáceres, os meses de outubro a abril têm valores de precipitação menores que 100,0 mm (Figura 4).

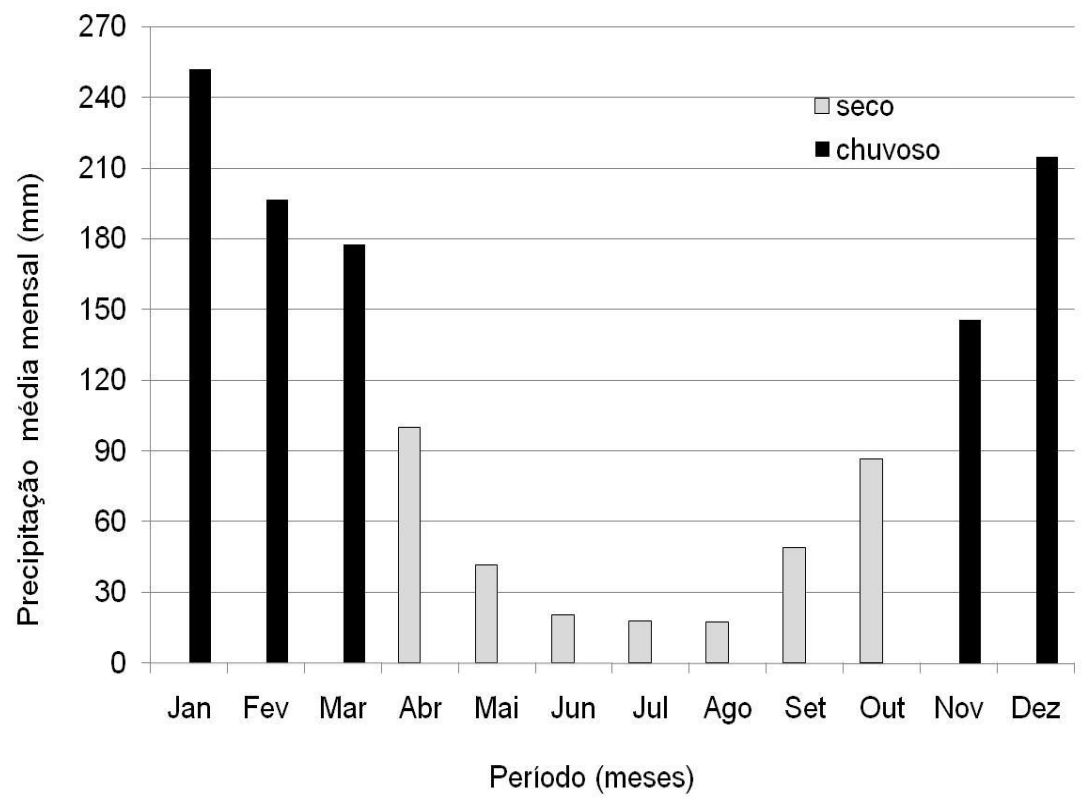

Figura 4 - Precipitação pluvial média mensal, no período seco e no chuvoso, para o município de Cáceres-MT, no período de 1971 a 2011 . Average monthly rainfall in the dry and rainy season, in the municipality of Caceres (MT) in the period 1971-2011.

A partir da Figura 4, observa-se que os meses de junho, julho e agosto apresentam as menores PPs, com valores menores que $30 \mathrm{~mm}$. Caioni et al. (2014) também observaram que esses meses correspondem ao trimestre de maior estiagem no município de Alta Floresta-MT, uma vez que apresentam longos períodos sem ocorrência de chuvas e/ou com chuvas insignificantes. Batistão et al. (2013) também obtiveram resultados semelhantes para 0 município de Juína-MT, sendo o mês de junho o de menor índice pluviométrico.

No presente estudo, verificou-se que os sete meses de período seco representaram $25,3 \%$ do total de chuvas no ano, e os cinco meses do período chuvoso representam $74,7 \%$ do total. Segundo Martins et al. (2011), as chuvas ocorridas no período seco, nesta região, têm insignificante contribuição ao regime pluvial.

O início do período chuvoso, geralmente, coincide com a época de preparo do solo para a implantação das culturas e, se não forem adotados critérios conservacionistas, pode haver perda de solo por erosão hídrica, devido à elevada erosividade nesta estação (Lima et al., 2008). A precipitação no período chuvoso, de novembro a março, foi de 197,3 $\mathrm{mm}$. Martins et al. (2011), em estudo sobre o regime pluvial do arco das nascentes do Rio Paraguai, para o período de 1961 a 2008, verificaram que Cáceres apresenta anual de 77,6 dias com chuva e 287,4 dias secos. Segundo os autores, a PP nos meses mais chuvosos é de cerca de $200 \mathrm{~mm}$, sendo que, nos meses de dezembro e janeiro, o número de dias chuvosos supera o de dias secos.

A PP mensal do período de 1971 a 2011, no período seco e chuvoso para Cáceres-MT, apresentada na Figura 4, mostra que o mês de janeiro tem a maior quantidade de PP. Marcuzzo et al. (2011) estudaram a PP total para o Estado de Mato Grosso e verificaram que o mês de dezembro é o mais chuvoso, junto com janeiro, fevereiro e março.

No período seco, considerando a PP nos meses de estiagem (abril a outubro), a seca foi classificada como extrema $(I>-0,6)$ na maior parte do período (Figura 5), com exceção apenas dos anos de 1971 e 1992, quando ocorreu seca intensa $(-0,4>\mathrm{I} \geq-0,6)$, devido à $\mathrm{PP}$ de 670,7 e 561,8 mm, no período de seca destes dois anos, respectivamente. 


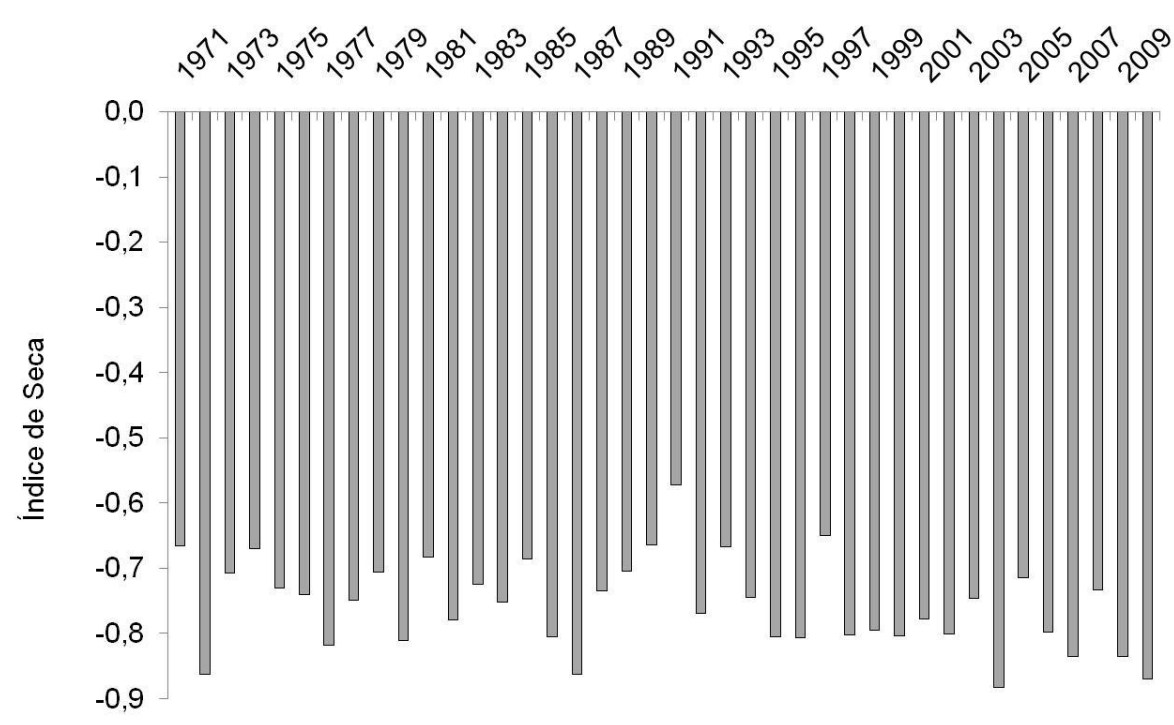

Figura 5 - Índice de seca para os sete meses de estiagem (abril a outubro), para o município de Cáceres (MT), no período de 1971 a 2011. Drought index for the seven months of dry season (April to October) to the municipality of Caceres (MT) in the period 1971-2011.

No período estudado, os anos de maiores índices de seca foram 2005 e 2011. Vale ressaltar que esse resultado se deve ao fato de que, nestes dois anos, as PPs no período seco foram as menores da série de dados em estudo, com valores de 22,2 e $24,5 \mathrm{~mm}$, respectivamente. Os resultados obtidos evidenciam a importância do conhecimento da PP na expressão do clima e do potencial agrícola da região em estudo, visando ao adequado planejamento de atividades agrícolas.

\section{Conclusões}

A precipitação pluvial total anual de Cáceres, no período de 1971 a 2011, é de $1.320,4 \mathrm{~mm}$, sendo que o mês com maior precipitação pluvial é janeiro (251,9 mm), e o mês com menor precipitação pluvial é agosto $(15,5 \mathrm{~mm})$.

Nos primeiros 20 anos da série em estudo (1971 a 1990), a precipitação pluvial apresenta valores médios anuais acumulados $(1.338,7 \mathrm{~mm})$ maiores do que dos últimos 21 anos (1991 a 2011), em que a precipitação pluvial anual é de $1.292,9 \mathrm{~mm}$.

Cáceres, em Mato Grosso, apresenta duas estações bem definidas, com período chuvoso de novembro a março e período seco de abril a outubro.

$\mathrm{Na}$ estação seca, de abril a outubro, a seca é classificada como extrema $(I>-0,6)$, na maior parte do período de estudo.

\section{Referências}

Batista AC (2000) Mapas de risco: uma alternativa para o planejamento de controle de incêndios florestais. Revista Floresta 30(1/2):45-54.

Batistão AC, Lavezo A, Pessoa MJG, Dallacort R, Carvalho MAC (2013) Distribuição temporal e probabilidade de ocorrência de chuva no município de Juína (MT). Revista Brasileira de Climatologia 13(9):258-270.
Bieras AR, Santos JZS (2006). Variabilidade e tendência da precipitação pluviométrica anual e mensal do município de Bebedouro (SP), no período de 1983 a 2003. Climatologia e Estudos da Paisagem, Rio Claro/SP 1(1/2):63-75.

Buriol GA, Estefanel V, Chagas AC, Eberhard TD (2007) Clima e vegetação natural do Estado do Rio Grande do Sul segundo o diagrama climático de Walter e Lieth. Ciência Florestal 17(2):91-100.

Cadavid García EA (1984) O clima no Pantanal Mato-grossense. Corumbá: Embrapa-CPAP. XXp. (Embrapa-CPAP. Circular Técnica, 14).

Caioni C, Caioni S, Silva ACS, Parente TL, Araújo OS (2014) Análise da distribuição pluviométrica e de ocorrência do fenômeno climático ENOS no município de Alta Floresta-MT. Enciclopédia Biosfera, Centro Científico Conhecer - Goiânia 10(19):2656-2666.

Collischonn W, Tucci CEM, Clarke RT (2003) Variabilidade temporal no regime hidrológico da bacia do rio Paraguai. Revista Brasileira de Recursos Hídricos, Porto Alegre, 8(1):201-211.

Cunha N, Junk WJ (2004) Year-to-year changes in water lavel drive the invasion of Vochysia divergens in Pantanal glassland. Applied Vegetation Science 7(1):103-110.

Diniz GL, Fonseca M, Campelo Jr JH (2008) Análise harmônica do regime de precipitação em duas localidades da baixada cuiabana. Grupo de Biomatemática IMECC - UNICAMP 18(1):37-48.

Forattini OP (2002) Culicidologia médica: identificação, biologia e epidemiologia. São Paulo: Edusp. 549p.

IBGE - Instituto Brasileiro de Geografia e Estatística. Cidades - Cáceres. 2007. Disponível em: http://www.ibge.gov.br/cidadesat/painel/painel.php?c odmun=510250 (Acesso em 19 set. 2014). 
Lima JSS, Silva AS, Oliveira RB, Cecílio RA, Xavier AC (2008) Variabilidade temporal da precipitação mensal em Alegre - ES. Revista Ciência Agronômica, Fortaleza, 39(2):327-332.

Marcuzzo FFN, Melo DCR, Rocha HM (2011) Distribuição espaço-temporal e sazonalidade das chuvas no estado do Mato Grosso. Revista Brasileira de Recursos Hídricos, Porto Alegre, 16(4):157-167.

Martins JA, Dallacort R, Inoue MH, Galvanin EAS, Magnani EBZ, Oliveira KC (2011) Caracterização do regime pluviométrico no arco das nascentes do Rio Paraguai. Revista Brasileira de Meteorologia 26(4):639-647.

Melo Junior JCF, Sediyama GC, Ferreira, P. A.; Leal, B. G.; Minusi, R. B (2006) Distribuição espacial da frequência de chuvas na região hidrográfica do Atlântico, Leste de Minas Gerais. Revista Brasileira de Engenharia Agrícola e Ambiental 10(2):417-425.

Nery JT, Martins ML, OF, Sant'ana JLN (2002) Variabilidade da precipitação no Brasil Meridional. Acta Scientiarum. Technology 24(6):1687-1695.

Neves SMAS, Nunes MCM, Neves RJ (2011) Caracterização das condições climáticas de Cáceres/MT - Brasil, no período de 1971 a 2009: subsídios às atividades agropecuárias e turísticas municipais. Boletim Goiano de Geografia. Goiânia-GO 31(2):55-68.

Pizzato JA, Dallacort R, Tieppo RC, Modolo AJ, Cremon C, Moreira PSP (2012) Distribuição e probabilidade de ocorrência de precipitação em Cáceres-MT. Pesquisa Agropecuária Tropical, Goiânia 42(2):137-142.
Salgueiro JHPB (2005) Avaliação de rede pluviométrica e análise de variabilidade espacial da precipitação: estudo de caso na bacia do rio Ipojuca em Pernambuco. 139 fls. Universidade Federal de Pernambuco, Recife-PE (Dissertação de Mestrado em Engenharia Civil).

Sansigolo CA (1996) Variabilidade interanual da estação chuvosa no estado de São Paulo. Revista Brasileira de Agrometeorologia 7(1):1001-105.

Silva JB, Basgalupp MP, Paz SR (2005) Comportamento das precipitações pluviais mensais em Pelotas, Rio Grande do Sul. Revista Brasileira de Agrometeorologia 13(1):155-159.

Silva JC, Heldwein AB, Martins FB, Trentin G, Grimm EL (2007) Análise de distribuição de chuva para Santa Maria, RS. Revista Brasileira de Engenharia Agrícola e Ambiental, Campina Grande/PB 11(1):67-72.

Silva JW, Guimaraes EC, Tavares M (2003) Variabilidade temporal da precipitação mensal e anual na estação climatológica de Uberaba-MG. Ciência e Agrotecnologia 27(3):665-674.

Soriano BMA, Galdino S (2005) Análise da distribuição da frequência mensal da precipitação para a sub-região da Nhecolândia, Mato Grosso do Sul, Pantanal, Brasil. Corumbá-MS: Embrapa Pantanal (Boletim de pesquisa, 34).

Sousa P, Nery JT (2002) Análise da variabilidade anual e interanual da precipitação pluviométrica da região de Manuel Ribas, Estado do Paraná. Acta Scientiarum. Technology 24(6):1707-1713.

Warrick AW, Nielsen DR (1980) Spatial variability of soil physical properties in the field. In: HILLEL, D. (Ed.) Applications of soil physics. New York, Academic Press. 350p. 